\title{
A Confession of Female Smokers in Medan about Their Smoking Habit (Cigarette and Chewing Tobacco): A Preliminary Study

\section{| Miskah Afriani ${ }^{1}$ | Yuzana Binti Mohd Yusop ${ }^{2}$ | | Harmy Bin Muhamed Yusof ${ }^{3}$ |}

\author{
1,2,3 Department Medicine, \\ University Sultan Zainal \\ Abidin, Kuala Terengganu, \\ Malaysia
}

miskahafriani@gmail.com

\begin{abstract}
Indonesia is the country with the highest number of smokers in ASEAN, with 65.19 million people. Equivalent is $34 \%$ of the total population of Indonesia in 2016. As 2545 women smoke, they smoke in various types, such as cigarettes, chewing tobacco, and vape (SDKI, 2018). Smoking prevalence among women is lower than that for men in most countries, but the rate is increasing rapidly from 4.2 percent to 6.7 percent in 2010-2013 (Riskesdas,2013).This research used qualitative approach. Semistructured interviews were held with 47 individuals from Medan city. A purposive sample was used who self-identified as female smokers in the past 30-days. Most of the participants who volunteered to take part in the study were over 25 years old. Tobacco users are divided into two focal categories which are cigarette smokers and chewing tobacco addicts, 31 reported as cigarette smokers, and 16 were reported having a chewing tobacco habit. Researches categorized cigarette users or smokers as CU and chewing tobacco users as CTU. The analysis of transcripts from the interviews revealed five main themes: 1) Personal problem lead to smoking (CU) 2) School friends' influences initiate the habit (CU) 3) Family tradition originate the chewing tobacco habit (CTU) 4) Prevent egoistic status from the tribe (CTU) and 5) Intent and struggle to quit but unsuccessful for $\mathrm{CU}$ but not CTU. Acclimatizing health promotion awareness and activities shall be concentrate on such as oral health, quit smoking and chewing tobacco program as well as motivational improvement approach to quit the smoking KEYWORDS

Female smokers; cigarette smoking; chewing tobacco
\end{abstract}

\section{INTRODUCTION}

Indonesia is the country with the highest number of smokers in ASEAN, with 65.19 million people. Equivalent is $34 \%$ of the total population of Indonesia in 2016. The Philippines is the second-highest number of smokers, as 16.5 million people or $15.97 \%$ of the total population. Vietnam is in third place with 15.6 million smokers or $16,5 \%$ of the population (Katadata, 2019). However, it is now known that there are many hazardous compounds in cigarette smoke, which cause a great deal of morbidity. More than eight million people died prematurely as a result of smoking in 2017, consist of 7 million people who died from active smoking and one million people died prematurely from secondhand smoke (GBD, 2017). 
Men and women use tobacco for different reasons. According to WHO, women smoking due to it is a good way to control weight, women are particularly sensitive to weight gain at all stages of smoking and to increase self-esteem (World Health Organization - Department of Gender Women and Health, 2010). In otherwise, women tend to fail to stop smoking related to emotional changes more often than men, especially when menstruation. In the USA, women smoking for control weight gain which is obese young women have a two times higher probability of developing severe nicotine addiction, have a high level of anger, depressive mood, anxiety, and perceived stress were all predictive of fall to quit smoking, women smoke after negative life experiences and smoking being a mechanism of emotional escape (Allen et al., 2014)(Rigbi et al., 2011). Another research in China, smoking associated with peer smoking was the most consistent correlate of smoking among Chinese girls. Among Chinese women, partner smoking, jobrelated stress, and exposure to cigarettes made for women were consistent correlates of smoking (Ding et al., 2014)). Similarly In Indonesia, the most predictor factors about having close friends who smoke cigarettes and desire to be accepted and become a part of a peer group and then followed by parental smoking habits (mother as a model to smoke), a positive image of smokers and smoking and got promotion cigarettes(Karina, 2009)

According to the Indonesian Demographic and Health Survey (2018), 2545 women smoke. they smoke in various types, such as cigarettes, chewing tobacco, and vape (SDKI, 2018). Smoking prevalence among women is lower than that for men in most countries, but the rate is increasing rapidly. Men smoke nearly five times as much as women, but the ratios of female smoking prevalence rates vary dramatically, research showed the prevalence of smoking in men is 16 times higher $(65.8 \%)$ than women $(4.2 \%)$ (INFODATIN, 2013). In 2010-2013, female smokers increased from 4.2 percent to 6.7 percent (Riskesdas,2013).

Chewing tobacco is widely used by certain tribes, such as Toba, Karo, and Simalungun. This phenomenon becomes something interesting because the consumption of chewing tobacco is widely used by women of reproductive age. Previously, the use of chewing tobacco was only used by elderly women. Usually, tobacco is consumed together with sirih or betel leaves.

The factors of consumption tobacco with cigarettes and chewing would be known in this study. Research about smoking for women much has been written, but more research from a representative sample in Medan is needed to better understand the reasons for tobacco consumption for adult women in Medan.

\section{RESEARCH METHODS}

Semi-structured interviews were held with 47 individuals from Medan city. A purposive sample was used who self-identified as female smokers in the past 30-days. According to WHO, daily smokers is someone who smokes any tobacco product at least once a day (WHO, 2008). Most of the interviews lasted for about 15 minutes. All real names were modified to protect participants' confidentiality. Interviews were recorded and transcribed. Most of the participants who volunteered to take part in the study were over 25 years old. The participants explained perfectly their own experiences as female smokers. Of the 47 female smokers, 31 reported as cigarette smokers, and 16 were reported having a chewing tobacco habit. In this study researches categorized cigarette users or smokers as CU and chewing tobacco users as CTU. Potential participants were provided with information about the study, and those who decided to participate gave informed consent. Confidentiality was assured, and the anonymity of the participants was protected. 


\section{Participants Recruitment}

The study was conducted between 15 to 31 December 2019. Purposive samples of female respondents for interviews were recruited through the Program Study of Psychology Faculty of Public Health, Helvetia University in Medan. The advertisements placed at the notice board of Simalingkar Medan Tuntungan were addressed to anyone willing to participate in the study, particularly over 18 years old. In this study, a participant who had been exercising tobacco intake (any kind) at the time of the study and for at least 1 month was a smoker was defined as a current tobacco user. For this study we refer to classification by WHO (2008), daily smokers are someone who smokes any tobacco product at least once a day.

\section{Analysis}

The evaluation of the data attaches to the established procedure of narrative analysis. This method may perhaps help in identifying, analyzing, and reporting summaries within data. Labov and Waletzky (1997) enunciated that narrative analysis focus on the ordinary stories people tell as a way to share everyday experiences. To begin with, the researchers viewed the 47 interview transcripts to identify items that pointed to the existence of potential themes. This involved a case by case analysis, trailed by a cross-case analysis of shared themes (see Table 2). In this study, the aim is to explore the issues in a simplistic pattern through background history and current situation among female smokers in Medan. The purpose of this analysis was to present an ostensible explanation of the relevant issues and themes which capture the views and experiences involved among female smokers. The analysis exposed a variety of information and will be centered on the objectives of the study. The themes that emerged during the analysis of each participant's transcript were compared to interpret what were felt to be the most significant experiences. For this analysis, first of all, the researchers looked for items within the interview transcripts that pointed to the existence of potential themes. The emerging themes were ordered in preliminary lists, which were later put into interconnected clusters.

\section{Demographic}

The total smokers in Medan that took part in the study were female $(n=47)$. Researchers have segregated age range for the participants starting from 25 and above 50. Both ranges between 31-35 years $(n=10)$ and over 50 years $(n=11)$ of age contributed as the bigger range for being participants of this study. The least number of participants age around 4145 years $(n=3)$. The socio-demographic are depicted in Table 1 . Most of the participants married with $87.2 \%(n=41)$. The single smokers were $3(6.4 \%)$ while others count up as 3 $(6.4 \%)$ widows or divorcees. The majority of smokers are working $(\mathrm{n}=27)$ and the balance is housewives $(n=20)$. Several ethnic groups such as Karo $(40.4 \%)$, Javanese $(29.8 \%)$, Batak (19.1\%), Padang (6.9\%), and Malay (4.3\%) have been involved and speak on behalf of female smokers in Medan.

\section{Tobacco Consumption}

Focal basic questions were asked to the female smokers in this study. The questions mainly demanded participants to explain the purpose of taking tobacco and for what reason that influences them to do it. And researchers insisted them to recall their tobacco consumption at present and have they ever tried to quit. They have explained that there were two types of tobacco consumption involved among the participants. The researchers have categorized 
them as cigarettes user (CU) and chewing tobacco users (CTU). The amount of CU which are $66.0 \%(n=31)$ and is higher as compared to CTU $35.0 \%(n=16)$. One of the main questions examining the duration they have consumed tobacco in months. A majority $(n=22)$ of them have been consuming tobacco for more than a year and to be specified 1336 months (46.8\%) and followed by $29.8 \%$ using it for more than 36 months. To quantify the amount of tobacco intake researchers set apart the question into the number of days. The main question was asked to get the number of cigarettes that took by the participants in this study. The researches have categorized them into three groups for their given answer. For $\mathrm{CU}$, most of the participants $(\mathrm{n}=21)$ took more than 10 cigarettes per day. Twelve of the participants enduring a habit of chewing tobacco less than five times a day dominated this group. Slightly surprise when there were four participants confessed chewing tobacco for more than 10 times a day.

Table 1. Demographic Characeristic Female Tobacco Consumer

\begin{tabular}{lll}
\hline Demographic & Frequency & Percentage \% \\
\hline Gender & & \\
Female & 47 & 100.0 \\
\hline Age & & \\
25 - 30 years & 7 & 14.9 \\
31 - 35 years & 10 & 21.3 \\
36 - 40 years & 8 & 17.0 \\
41 - 45 years & 3 & 6.4 \\
46 - 50 years & 8 & 17.0 \\
51 and above & 11 & 23.4 \\
\hline Marital status & & \\
Single & 3 & 6.4 \\
Married & 41 & 87.2 \\
Widow/Divorcee & 3 & 6.4 \\
\hline Employment & & \\
status & & \\
Employees & 27 & 57.4 \\
Housewives & 20 & 42.6 \\
\hline Ethnics & & \\
Karo & 19 & 40.4 \\
Batak & 9 & 19.1 \\
Javanese & 14 & 29.8 \\
Malay & 2 & 4.3 \\
Minang & 3 & 6.9 \\
\hline n= 47 & &
\end{tabular}


Table 2. The Record Of Tobacco Intake Among Participants In The Study

\begin{tabular}{lll}
\hline Record of tobacco consumption & Frequency & Percentage \% \\
\hline Type of tobacco consumption & & \\
Cigarettes & 31 & 66.0 \\
Chewing tobacco & 16 & 34.0 \\
\hline Length of tobacco consumption & & \\
0 - 6 months & 3 & 6.4 \\
7 - 12 months & 8 & 17.0 \\
13 months - 36 months & 22 & 46.8 \\
More than 36 months & 14 & 29.8 \\
\hline Quantity of tobacco intake & & \\
Cigarettes & & \\
Less than 5 cigarettes per day & 5 & 10.6 \\
5 to 10 cigarettes per day & 5 & 10.6 \\
More than 10 cigarettes per day & 21 & 44.7 \\
Chewing tobacco & & \\
Less than 5 times per day & 12 & 25.6 \\
5 to 10 times per day & 0 & 0 \\
More than 10 times per day & 4 & 8.5 \\
\hline n=47 & &
\end{tabular}

\section{RESULT AND DISCUSSION}

The analysis of the data adhered to the established procedure of narrative analysis. To begin with, the researcher viewed the 47 interview transcripts to identify items that pointed to the existence of potential themes. This involved an item by item analysis, followed by a cross-item analysis of shared themes. In this study, researchers have discovered that two ways and most popular tobacco consumption for female smokers in Medan are smoking cigarettes and chewing tobacco. Researchers split the analysis into two dissimilar categories which are CU cluster and CTU cluster so that we may see in detail the trending of this matter in Medan. Most of them have much experience and background as smokers in their lives. The analysis of transcripts from the interviews revealed five main themes: 1) Personal problem lead to smoking (CU) 2) School friends' influences initiate the habit (CU) 3) Family tradition originate the chewing tobacco habit (CTU) 4) Prevent egoistic status from the tribe (CTU) and 5) Intent and struggle to quit but unsuccessful for CU but not CTU.

1. Personal problem lead to smoking (CU)

Almost half of the participants had confessed that cigarette smoking habit originates from their problems. Many did not reveal the problem but quite a number said because of family problems and especially with their spouse or husband. The following quotes from the participants agreed that they had been through the same problems too.

- "I start to smoke whenever I have a problem, especially a family problem." Participant 4 (nurse)

- "I need to smoke to handle my stress; I have so many problems. I can avoid my stress with smoking." Participant 8 (housewife) 
- "I used to smoke when I have a problem with my husband. I can feel calm when I smoke." Participant 20 (administrator)

Minority declared that they are having a financial problem and with their work colleagues or employer. The majority of them hide the habit from their spouse. They did not smoke in front of the spouse at home or public but with friends. They said that by light-up the cigar they could relieve their life-pressure at the moment. Javanese $(n=14)$ dominated as a female smoker for this category as compared with other ethnicities and follow by Batak $(n=8)$. The remainder's ethnic contribute as marginal for this group. Merely five of the female smokers are housewives. Almost all of the $\mathrm{CU}$ is working in various professions in Medan.

2. School friends' influences initiate the habit (CU)

Most female smokers get started since adolescence and continue to smoke into adulthood. There are many indications of what causes adolescents to smoke. This study conducted among female smokers in Medan has pointed out that peer pressure plays an essential role in the establishment of their smoking habit. At the beginning of this analysis, researchers have remarked that the participants declared that they began their habit during their school phase. In this situation, we can see that the participants want an attachment and belonging to their peers. Therefore, they feel pleased that the group recognizes them as the rest of the group members. The circumstances may have a very positive effect on their self-esteem but carry out the unhealthy habit like smoking to be recognized contribute to a long term risk to the members. The majority of all the females CU are married and working in various fields in Medan. The following extract from the participants:

- "I started my habit, which is smoking when I was in school. I want to be accepted in the group so I have to follow my gang." Participant 30 (cashier)

- "I have no choice and go along with my friends. If they smoke, I smoke with them too." Participant 7 (administrator)

- "When they start to offer me a cigarette in school, I take the challenge." Participant 37 (administrator)

3. Family tradition originate the chewing tobacco habit (CTU)

However, for chewing tobacco users, they responded and said that they carry out their habit because of family traditions. A long-established practice passed from one generation to another. The practice has been implemented whenever the Karo ethnic are having celebration either with family or community. Besides, one of the leading influences on the behavior rooted in their relatives and grandparents. In this study majority of them have declared that either their mother or grandmother will show and support their young generation technique of chewing tobacco. They encourage the young one to try to munch the tobacco. They take the opportunity to try and start the habit. Therefore, they cannot be left behind the tradition of their ethnicity. Follow the tradition is one of the requirements to feel well-mannered about themselves and the sense of belonging to the tribe tightly. All of them are ethnic Karo. Almost all the CTU are housewives. Several participants provided similar statements from the interviews as follows. 
- "My grandmother demonstrate and teach me how to chewing the tobacco when I was a kid." Participant 5 (housewife).

- "I try it for the first time during a gathering with family, everyone encourages me and I feel ok with it." Participant 9 (housewife).

- "My mum shows me how to munch tobacco. Why not I try." Participant 17 (housewife).

4. Prevent egoistic status from the tribe (CTU)

In this interview, the entire participants professed that if they refuse to chew the tobacco given, most of the family members will spot them as a stranger for not following the tradition. Generally, in growing personal character an ecological encouragement has played a relevant role in it. Beyond doubt when the surroundings keep budging them to do it, they will do. One more important issue, Karo female would feel shame if the relatives or tribe will badge them as an egoistic because they refuse to continue the tradition. Sample responses for this theme as follow:

- "Me, I am not chewing it regularly last time but now every day. But when we get together I mean family I will chew the tobacco. If you object to doing it, they will grade you as arrogant or egoistic because you don't want to continue the tradition." Participant 31 (housewife)

- "They will feel you are creepy because try to avoid chewing tobacco" Participant 40 (housewife)

5. Intent and struggle to quit but unsuccessful for CU but not CTU

Those who smoke the cigar (CU) are working in diverse professions in Medan $(n=25)$. Only six are housewives. Javanese conquers the category follow by Batak, Karo, Padang, and Melayu. The majority of them were married. One of the questions about leaving the smoking habit was asked. Nearly all of them $(n=30)$ have the intention to quit. Quite a number have tried several times but failed to do so. According to them the average day they can stop having a cigar is 3 days. Then craving habits will reappear so they unable to control having cigarettes. Peer smoking among work colleagues is a stronger predictor of smoking too. In these circumstances, the participants initiate tobacco use because they believe that it helps them cope with their problems. For CTU the results are going against $\mathrm{CU}$, mostly. Almost all chewing tobacco users have no intention to quit. Ethnic Karo wants to retain their tradition. They certainly not worry about health issues. For them, chewing tobacco has a great impact, especially oral health.

- "I have tried 1 time to quit but I failed." Participant 26 (administrator)

- "I want to try. I have made an effort to stop twice but unfruitful. " Participant 26 (administrator)

- "I have tried 3 times to quit. But I gave up" Participant 36 (civil officer).

The present study aimed to expose female tobacco consumers in Medan. As we know that in Indonesia the prevalence of smokers among males is extensively higher as compared with females (Kusumawardani et al., 2018). However, the increase in the female smoker is worrying. In 2013, the prevalence of male smoking increased from $65.8 \%$ in 2010 to $66 \%$. Likewise, the proportion of adult female smokers increased from $4.2 \%$ in 
2010 to $6.7 \%$. Overall, the prevalence of smoking in men and women has increased (Tobacco Control Support Center, 2015). The proportion of men who consume cigarettes is greater than chewing tobacco which is $64.9 \%$ and $1.1 \%$. on the contrary, it appears in women, the proportion of women who consume chewing tobacco is more than twice that of women who consume suction tobacco which is $4.6 \%$ and $2.1 \%$ (INFODATIN, 2013).

Our main findings in this study indicate that tobacco users are divided into two focal categories which are cigarette smokers and chewing tobacco addicts. Tobacco Atlas (2015) has reported that even a smaller number of female smoke in Indonesia, there are still more than 1,957,600 women who smoke cigarettes each day, making it a continuing and terrible public health risk to the country. One of the risks is the burden of cancer. And one of the studies being conducted in ASEAN and almost 10,000 patients had newly diagnosed with cancer in Indonesia (Jan et al., 2012).

Several cigarette users jump to the habit when they have personal issues with their family and at work. Job stress was found to be related to smoking status and nicotine dependence (Son et al., 2016). (Manabete, S.S., John, C. A., Makinde, A. A., \& Duwa, 2016) also characterize wrong ways to deal with job stress to include smoking, using pills, drugs, and several other immoral behaviors employees satisfying every minute of the day with activities to escape problems. Besides, the majority of them begin the habit since they were in school. Normally among male smokers, smoking did not affect their friendship but increased the chance of making more friends in school. However female smokers felt that they would have fewer friends as compared with males (Caszo et al., 2015) and prefer to attach closely to the clique. Cigarette users fail to disclose the habit to their spouse and family too (Jane C. Orcullo \& Hui San, 2016).

There is a good sign for cigarette users because they did have the intention to quit and even attempted several times were failed. However, ethnic Karo is considering as chewing tobacco users because of tradition. (Amtha et al., 2014) have corroborated that the habit of tobacco and betel chewing is most commonly seen in rural areas of Indonesia, particularly North Sumatra, Dayak, and Papua. We discovered that the users start to get the habit of their family members as well as the Karo community. For Karo, the habit started when they were encouraged by their family members to munch the tobacco. The family would demonstrate and motivates them to try especially during the festival ceremony. According to Amtha et al., (2014) this habit is well thought-out to be a sign of respect for plants, and it usually engaged in during traditional events. In these circumstances, family attitudes condone chewing tobacco habit. The risk that a person starts chewing tobacco habit is often higher if any family members have it. For them, each generation has to bring the tradition along, and certainly, they have disclosed the habit to everyone. Awkwardness problem in here, the entire of Karo participants have no intention to quit the habit. Both methods of tobacco consumption contribute to oral health issues because most of them seem to have less awareness of the connectivity between cancer and their habit. Many studies have revealed the association between tobacco consumption and high oral cancer incidence. Awan and Patil (2016) have explored that many studies reported sirih or betel leave quid as a risk factor for oral cancer as well as of chewing tobacco habit. Women who consume chewing tobacco 1-3 times per day have a risk of having a baby with low bird weight as $30 \%$. And mothers who consume chewing tobacco for more than 5 years are at risk of giving birth to babies with a low weight of $40 \%$ (Martalena, 2019). Besides, the number of cases of tobacco-related diseases by sex in 2013 with a total of 962,403 cases 
(570,342 in men and 387,885 in women). Chronic obstructive pulmonary disease is the most common type of tobacco-related disease, followed by severe low birth weight baby disease, coronary heart disease, stroke and lung tumors, bronchus, and trachea (INFODATIN, 2013) Although smoking is associated with many diseases and has negative consequences, stop smoking any kind of tobacco product still allows for smoking-related diseases and deaths to be evaded. To improve public-health goals, it is essential to reduce the prevalence of smoking among males and females through smoking prevention as well as by increasing successful smoking-cessation attempts. Based on this outcome, it is suggested to enhance awareness among female smokers by organizing health promotion activities and interventions to reduce the number of smokers.

\section{CONCLUSION}

The results of this study grow concerns about people who initiate tobacco use because they believe that it helps them cope with personal problems. Social influences and peer pressure have been shown to be a powerful principle of smoking habit too. Besides, the findings highlight the idea that female Karo ethnic inheritance chewing tobacco habit and they prefer to retain and continue the tradition in this contemporary era. Regardless of their status as housewives, self- employed even professionals were little, they prefer to retain and continue their tradition. Acclimatizing health promotion awareness and activities shall be concentrate on such as oral health, quit smoking and chewing tobacco program as well as motivational improvement approach to quit the smoking.

\section{REFERENCES}

Allen, A. M., Oncken, C., \& Hatsukami, D. (2014). Women and Smoking: The Effect of Gender on the Epidemiology, Health Effects, and Cessation of Smoking. In Current Addiction Reports. https://doi.org/10.1007/s40429-013-0003-6

Amtha, R., Razak, I. A., Basuki, B., Roeslan, B. O., Gautama, W., Puwanto, D. J., Ghani, W. M. N., \& Zain, R. B. (2014). Tobacco (Kretek) smoking, betel quid chewing and risk of oral cancer in a selected Jakarta population. Asian Pacific Journal of Cancer Prevention. https://doi.org/10.7314/APJCP.2014.15.20.8673

Caszo, B., Khair, M., Mustafa, M. H., Zafran, S. N., Syazmin, N., Safinaz, R. N. I., \& Gnanou, J. (2015). Common misconceptions and future intention to smoke among secondary school students in Malaysia. Asian Pacific Journal of Cancer Prevention. https://doi.org/10.7314/APJCP.2015.16.3.1159

Ding, D., Gebel, K., Oldenburg, B. F., Wan, X., Zhong, X., \& Novotny, T. E. (2014). An early-stage epidemic: A systematic review of correlates of smoking among Chinese women. International Journal of Behavioral Medicine. https://doi.org/10.1007/s12529013-9367-1

GBD 2017 Risk Factor Collaborators. Global, regional, and national comparative risk assessment of 84 behavioural, environmental and occupational, and metabolic risks or clusters of risks for 195 countries and territories, 1990-2017: a systematic analysis for the Global Burden of Disease Study 2017. The Lancet. 8 Nov 2018;392:1923-94. doi: http://dx.doi.org/10.1016/S0140-6736(18)32225-

INFODATIN. (2013). Perilaku Merokok Masyarakat Indonesia. KEMENKES RI. www.pusdatin.kemkes.go.id 
Jan, S., Kimman, M., Kingston, D., \& Woodward, M. (2012). The socioeconomic burden of cancer in member countries of the association of southeast asian nations (ASEAN) Stakeholder meeting report. Asian Pacific Journal of Cancer Prevention. https://doi.org/10.7314/APJCP.2012.13.2.407

Jane C. Orcullo, D., \& Hui San, T. (2016). Understanding Cognitive Dissonance in Smoking Behaviour: A Qualitative Study. International Journal of Social Science and Humanity. https://doi.org/10.7763/ijssh.2016.v6.695

Karina, B. (2009). Factors for young adult woman to smoke lights or non lights cigarette. 90-107.

Kusumawardani, N., Tarigan, I., Suparmi, \& Schlotheuber, A. (2018). Socio-economic, demographic and geographic correlates of cigarette smoking among Indonesian adolescents: results from the 2013 Indonesian Basic Health Research (RISKESDAS) survey. Global Health Action. https://doi.org/10.1080/16549716.2018.1467605

Manabete, S.S., John, C. A., Makinde, A. A., \& Duwa, S. T. (2016). JOB STRESS AMONG SCHOOL ADMINISTRATORS AND TEACHERS IN NIGERIAN SECONDARY SCHOOLS AND TECHNICAL COLLEGES. International Journal of Education, Learning and Development.

Martalena. (2019). Analysis Nicotine of Tobacco (Nicotiana Tabacum) Used as Chewing Tobacco and Effect of Consumption Events Low Birth Weight (Lbw) In the District Lau Baleng Karo District North Sumatra. 1.

Rigbi, A., Yakir, A., Sarner-Kanyas, K., Pollak, Y., \& Lerer, B. (2011). Why do young women smoke VI. A controlled study of nicotine effects on attention: Pharmacogenetic interactions. Pharmacogenomics Journal. https://doi.org/10.1038/tpj.2010.15

World Health Organization - Department of Gender Women and Health. (2010). 10 Facts on Gender and Tobacco. World Health Organization (WHO).

The Tobacco Atlas. https://tobaccoatlas.org/country/indonesia/ 2015.

Widowati. Indonesia, Negara dengan Jumlah Perokok Terbanyak di Asean. retrieved from: https://databoks.katadata.co.id/datapublish/2019/05/31/indonesia-negara-denganjumlah-perokok-terbanyak-di-asean 